\title{
Comparative Study of Vaginal Misoprostol and Intracervical Dinoprostone Gel for Induction of Labour
}

\author{
Sneha Shahaji Jadhav ${ }^{1}$, Arti Siddharth Shirsat ${ }^{2}$, Neelesh Sharad Risbud ${ }^{3}$ \\ ${ }^{1}$ Department of Obstetrics and Gynaecology, Deenanath Mangeshkar Hospital, Pune, Maharashtra, India. \\ ${ }^{2}$ Department of Obstetrics and Gynaecology, SKN Medical College and Hospital, Pune, Maharashtra, India. \\ ${ }^{3}$ Department of Obstetrics and Gynaecology, SKNMC \& GH, Pune, Maharashtra, India.
}

\section{ABSTRACT}

\section{BACKGROUND}

Induction of labour is an intervention to artificially stimulate uterine contractions leading to progressive dilation and effacement of cervix. This results in delivery of foetus before the onset of spontaneous labour. Dinoprostone gel and Misoprostol are commonly used drugs for cervical ripening. We wanted to compare the efficacy and safety of Dinoprostone with Misoprostol for cervical ripening and induction of labour in women with unfavourable cervix.

\section{METHODS}

This is a prospective study conducted among 200 antenatal women who required induction of labour for different indications. 100 patients with an indication for induction were given $25 \mathrm{mcg}$ of intravaginal misoprostol and repeat dose up to a maximum of 3 doses every 4 hours as needed. The other 100 patients were given 0.5 mg of intracervical dinoprostone gel and repeated for a maximum of 3 doses every 6 hours as needed. Progress of labour was monitored. Bishop score was determined.

\section{RESULTS}

Postdatism was the most common cause of induction (45\% and 58\%) in both the groups. The difference in values of mean induction delivery time in both primipara and multipara was not significant statistically for both the drugs. Study showed that the number of caesarean sections was significantly ( $\mathrm{p}$ value 0.028 ) reduced with the use of misoprostol for induction of labour. The most common indication for operative delivery was foetal distress $11 \%$ in the misoprostol group and $17 \%$ in the dinoprostone group). Maternal and foetal complication rate in both the groups was similar.

\section{CONCLUSIONS}

Caesarean rate was significantly less with intravaginal misoprostol group compared to dinoprostone group. Other factors had no statistical significance. Vaginal misoprostol is thus a better option for induction of labour.

\section{KEY WORDS}

Induction of Labour, Misoprostol, Dinoprostone Gel, Bishop Score
Corresponding Author: Sneha Shahaji Jadhav, Plot No. 16, GAT No. 58, Golden Colony Gend, Vasti Karad Road, Pandharpur Dist., Solapur, Maharashtra, India. E-mail: jsneha608@gmail.com

DOI: $10.14260 / j e m d s / 2020 / 531$

How to Cite This Article:

Jadhav SS, Shirsat AS, Risbud NS. Comparative study of vaginal misoprostol and intracervical dinoprostone gel for induction of labour. J Evolution Med Dent Sci 2020;9(34):2442-2446, DOI: $10.14260 / \mathrm{jemds} / 2020 / 531$

Submission 10-05-2020,

Peer Review 12-07-2020,

Acceptance 18-07-2020,

Published 24-08-2020.

Copyright (C) 2020 JEMDS. This is an open access article distributed under Creative Commons Attribution License [Attribution 4.0 International (CC BY 4.0)] 


\section{BACKGROUND}

Induction of labour at term to achieve a vaginal delivery is a commonly accepted obstetric intervention when continuation of pregnancy is deleterious for the mother or foetus or both. It is an intervention to artificially stimulate uterine contractions and thus leading to progressive dilation and effacement of cervix and delivery of foetus before the onset of spontaneous labour. ${ }^{1}$ In some $5-25 \%$ of pregnancies, there comes a time when the foetus and/or mother would be better off if the delivery was conducted. Advent of prostaglandins has revolutionized induction of labour. ${ }^{2}$ Many studies have shown the advantages of using vaginal prostaglandins in cervical priming and labour induction in terms of reduced inductiondelivery interval and lower operative rate compared to oxytocin alone. Prostaglandins alter the extracellular ground substance of the cervix, ripen the cervix and also increase the activity of collagenase in the cervix. They also allow for an increase in intracellular calcium levels, causing contraction of myometrial muscle. ${ }^{3,4}$ Labour induction with unfavourable cervix is often prolonged, tedious and may end up in induction failure. ${ }^{5}$ Hence, for more successful outcome, cervical ripening is required before induction of labour.

The FDA revised its labelling of misoprostol in April 2002 from contraindicated in pregnancy to contraindicated in pregnancy for the treatment and prevention of NSAID induced ulcers. ${ }^{4}$ Currently, two prostaglandin analogues, PGE1 (Misoprostol) and PGE2 (Dinoprostone gel) are available for cervical ripening. Dinoprostone is the drug of choice and is accepted for labour induction at term. Although safe and effective, it is expensive and requires refrigeration for storage. Misoprostol (15-deoxy-16-hydroxy-16 methyl-PGE1) was the first synthetic prostaglandin analogue to be made available for the treatment of peptic ulcer. It has been shown to be effective in cervical priming and labour induction. It is inexpensive, can be stored at room temperature and has few systemic side effects. ${ }^{6,7}$ Misoprostol is proposed for induction in WHO model list of essential medicines for labour induction at term to be used in low dose (25-50 microgram).

The artificial prostaglandin E2 i.e. Dinoprostone gel can be administered vaginally to induce labour but it is unstable at room temperature and is expensive. A minimum of six hours' time gap has to elapse after the dose for further management. ${ }^{8}$ Misoprostol has shown to be an effective and safe agent for induction of labour in many trials. A major adverse effect of the obstetrical use of Misoprostol is hyperstimulation of the uterus and foetal distress, but it is usually seen in cases where Misoprostol is given in higher doses. ${ }^{9}$

The present study is aimed to compare the efficacy and safety of Dinoprostone with Misoprostol for cervical ripening and induction of labour in women with unfavourable cervix.

\section{METHODS}

This is a prospective interventional study comparing the efficacy of intracervical dinoprostone gel with intravaginal misoprostol for cervical ripening for induction of labour. The study was undertaken for a period of 18 months from December 2015 to July 2017 in the Department of Obstetrics and Gynaecology of a tertiary care center. All eligible cases admitted in the antenatal ward and labour room were included in the study. 200 Antenatal women who required induction of labour for different indications were selected randomly on the basis of experience. Patients who needed induction were screened first by detailed history, thorough general, systemic and obstetric examination including per vaginum examination. Selection was finally done according to the inclusion and exclusion criteria given below.

\section{Inclusion Criteria}

1. Singleton foetus with cephalic presentation.

2. Over 34 weeks of gestation.

3. Reactive foetal heart pattern.

4. Unfavourable cervix bishop score $<4$.

5. No contraindication to vaginal delivery.

\section{Exclusion Criteria}

1. Women who are not giving consent.

2. CPD (Cephalo Pelvic Disproportion).

3. Previous LSCS or any scar on uterus.

4. Malpresentation.

5. Prior myomectomy or uterine unification surgery.

6. Malpresentation.

7. Multiple gestation.

8. Allergy to prostaglandins.

9. Abnormal foetal heart rate pattern.

10. Severe maternal medical disorders.

Antenatal patients were assigned to one of the following two groups by simple randomisation technique-

Group A- 100 patients with an indication for induction were given 25 mcg of intravaginal misoprostol and repeat dose for maximum 3 doses every 4 hours as needed. Women were examined 4 hourly intervals to know the improvement in Modified bishop's score. observations were continued as per decided schedule. Oxytocin drip started as per requirement.

Group B- 100 patients with an indication for induction were given $0.5 \mathrm{mg}$ of intracervical dinoprostone gel and repeated for a maximum 3 doses every 6 hours as needed. Cases were reviewed 6 hours after 1st instillation for the Modified bishop's score. If score is poor further instillation of dinoprostone gel was done and were reassessed every 6 hourly. Oxytocin drip was started as per requirement. Progress of labour was monitored with the help of Partogram in both the groups, when patients were in the Active stage of labour. Continuous electronic foetal heart rate and uterine contraction monitoring was made available for every case. Before induction of labour is carried out, Bishop score should be assessed and recorded, and a normal foetal heart rate pattern should be confirmed using electronic foetal monitoring. Bishop score should be reassessed 6 hours after vaginal PGE2 tablet or gel insertion, to monitor the progress of labour when contractions begin, or if she has had no contractions after 6 hours. 
The following were recorded-

- Induction- delivery time.

- Complications (Tachysystole, foetal distress).

- Operative intervention.

- Oxytocin drip.

- No of doses of the drug used.

- Mode of delivery.

- Amniotomy was done in the active phase.

- No sedatives or analgesics were used.

\section{Complications of Induction}

1. Uterine hyperstimulation - Overactivity of the uterus as a result of induction of labour. It is variously defined as uterine tachysystole (more than five contractions per 10 minutes for at least 20 minutes) and uterine hyper systole/ hypertonicity (a contraction lasting at least 2 minutes). These may or not be associated with changes in the foetal heart rate pattern (persistent decelerations, tachycardia or decreased short term variability)

2. Foetal distress

3. Failure of induction- Failure to establish labour after one cycle of treatment, consisting of the insertion of three vaginal PGE2 gel (1-2 mg) at 6-hourly intervals or three doses of intravaginal misoprostol of $25 \mu \mathrm{gm}$ at 4 -hour intervals.

\section{CTG Interpretation}

When reviewing the CTG trace, assess and document contractions and all 4 features of foetal heart rate: baseline rate; baseline variability; presence or absence of decelerations (and concerning characteristics of variable decelerations* if present); presence of accelerations. If there is a stable baseline foetal heart rate between 110 and 160 beats/minute and normal variability, continue usual care as the risk of foetal acidosis is low.

\section{Statistical Analysis}

The data was collected, tabulated and analyzed for various parameters and were compared. The statistical significance among all parameters was derived by the student $t$ test (unpaired t test).

\section{RESULTS}

\section{Indication for Induction of Labour}

This graph shows that postdatism was the most common cause of induction ( $45 \%$ and 58\%), others being preeclampsia and oligohydramnios.

\section{Induction Delivery Time (as per Parity)}

Unpaired t test is applied. P value being 0.464 shows that the difference in the values of mean induction delivery time in both primipara and multipara was not significant statistically. Unpaired t test is applied. P value being 0.431 shows that the difference in the values of mean induction delivery time in both primipara and multipara was not significant statistically. Study showed that the number of caesarean sections was significantly ( $p$ value 0.028 ) reduced with group A i.e. with use of misoprostol for induction of labour. (17\% and 28\%) Majority of patients in both the groups had full term normal vaginal deliveries $(75 \%$ and $60 \%)$. The rate of instrumental deliveries was similar. Table 4 shows that the most common indication for operative delivery was foetal distress (11\% in misoprostol group and $17 \%$ in dinoprostone group). Table 5 shows us that both the groups had statistically similar complications. Hyperstimulation of the uterus due to induction was a common complication and statistically not significant between misoprostol and dinoprostone gel. ( $p$ value -0.238 using chi square test)

\begin{tabular}{|cccccc|}
\hline Para & $\begin{array}{c}\text { No. of } \\
\text { Cases }\end{array}$ & $\begin{array}{c}\text { Min. Duration } \\
\text { (HRS) }\end{array}$ & $\begin{array}{c}\text { Max. Duration } \\
\text { (HRS) }\end{array}$ & $\begin{array}{c}\text { Mean } \\
\text { +/_Sd }\end{array}$ & P Value \\
M & \multirow{2}{*}{37} & 10 & 19 & $\begin{array}{c}15.76+/ \\
-2.43\end{array}$ & 0.464 \\
P & \multirow{5}{*}{63} & 7 & 27 & $\begin{array}{c}16.25+/ \\
-3.60\end{array}$ \\
\hline
\end{tabular}

\begin{tabular}{|cccccc|}
\hline Para & $\begin{array}{c}\text { No. of } \\
\text { Cases }\end{array}$ & $\begin{array}{c}\text { Min. Duration } \\
\text { (HRS) }\end{array}$ & $\begin{array}{c}\text { Max. Duration } \\
\text { (HRS) }\end{array}$ & $\begin{array}{c}\text { Mean+/- } \\
\text { Sd }\end{array}$ & P Value \\
Multi & 29 & 9 & 20 & $\begin{array}{c}15.79+/- \\
2.93\end{array}$ & 0.431 \\
Primi & 71 & 7 & 30 & $\begin{array}{c}16.47+/- \\
4.45\end{array}$ & \\
\hline \multicolumn{5}{c}{ Table 2. Dinoprostone Group } \\
\hline
\end{tabular}

\begin{tabular}{|ccccc|}
\hline & & Group & & Total \\
Type of delivery & MISO & DINO & \\
& Emergency LSCS & 17 & 28 & 45 \\
& FORCEPS & 4 & 6 & 10 \\
& Normal vaginal & 75 & 60 & 135 \\
Total & Ventouse & 4 & 6 & 10 \\
\hline \multicolumn{5}{c}{ Table 3. Mode of Delivery } \\
\hline p value $=0.028$ for LSCS & 100 & 100 & 200 \\
\hline
\end{tabular}

\begin{tabular}{|ccc|}
\hline Indication & Misoprostol Group & Dinoprostone Group \\
Arrest of descent & 1 & 0 \\
Failure of induction & 3 & 5 \\
Foetal distress & 11 & 17 \\
Maternal exhaustion & 4 & 7 \\
MSL & 15 & 7 \\
Non-Progress of Labour & 2 & 0 \\
(Cervical Dystocia) & 3 & 5 \\
Non-Reactive CTG & 0 & 2 \\
\hline Severe PIH & Table 4. Indications for Operative Deliveries \\
\hline \multicolumn{2}{|c}{} \\
\hline
\end{tabular}

\begin{tabular}{|ccc|}
\hline Type of Complication & Misoprostol Group & Dinoprostone Group \\
4th Degree Perineal Tear & 1 & 1 \\
Cervical Tear & 0 & 1 \\
Hyperstimulation & 13 & 7 \\
Post-Partum Haemorrhage & 9 & 7 \\
\hline \multicolumn{2}{|c|}{ Table 5. Complications in the Mother } \\
\hline
\end{tabular}

\begin{tabular}{|ccc|}
\hline Type & Misoprostol & Dinoprostone \\
BA & 1 & 1 \\
FSB & 2 & 0 \\
Hyperbilirubinemia & 1 & 2 \\
IUD & 1 & 0 \\
MAS & 1 & 7 \\
MSL & 15 & 7 \\
NICU & 9 & 7 \\
Total & $\mathbf{3 0}$ \\
\hline \multicolumn{3}{c}{ Table 6. Foetal Complications } \\
\hline
\end{tabular}

Table 6 shows that the NICU admissions and meconium stained liquor were the common foetal complications. The rate of meconium stained liquor was $15 \%$ in the misoprostol group 
and 7\% in the dinoprostone group. The NICU admissions were similar in both groups with no statistical difference.

\section{DISCUSSION}

Present prospective study of comparison between intravaginal Misoprostol and intracervical Dinoprostone gel for induction of labour was conducted at a tertiary care Centre from December 2015 to July 2017. 200 patients were recruited for the study as per the selection criteria.

This study shows that Post-datism was the most common cause of induction in both the groups ( $45 \%$ and $58 \%$ ) others being pre-eclampsia (15\% and 18\%) and oligohydramnios (16\% and $4 \%)$. M Prajer et al ${ }^{10}$ in their study had majority of inductions with Post maturity as the main indication in 65 patients (34\%) with misoprostol and in 77 patients (39\%) others being spontaneous rupture of membranes and foetal and maternal indications. The present study shows that the mean induction delivery time of both the groups is almost the same and the time interval difference in both the groups was not statistically significant. M Prajer et al $^{10}$ in their study noted that the mean induction delivery time in both the groups was similar and not statistically significant regardless of the parity.

The no of caesarean sections was significantly ( $p$ value 0.028 ) reduced with group A i.e. with use of misoprostol for induction of labour. (17\% and 28\%) Majority of patients in both the groups had full term normal vaginal deliveries $(75 \%$ and $60 \%$ ). The rate of instrumental deliveries was similar. Kadanalli S in 1996 and Ozkan S11 in 2009 have found low caesarean rates with common indications for induction of labour being post-term pregnancy. Misoprostol low dose was used which led to long delivery intervals.

The common indication for operative delivery was foetal distress $(11 \%$ and $17 \%)$ in both the groups. Failure of induction was seen in $3 \%$ and $5 \%$ of patients of both the groups. There were $13 \%$ patients in the misoprostol group and $7 \%$ patients in the Dinoprostone group who had hyperstimulation of the uterus. Nanda et al ${ }^{12}$ reported that the increased efficacy of low dose of misoprostol, the uterine contraction abnormalities, abnormal foetal heart rate (FHR) pattern and meconium passage occurred more significantly in the misoprostol group as compared with the dinoprostone group. A similar study by Prager et $\mathrm{al}^{10}$ with Foleys catheter in the third arm in addition to the prostaglandin regimens observed that there was a tendency towards more frequent caesarean section in response to foetal distress among the women administered dinoprostone and more frequent dystocia in those receiving misoprostol. Hofmeyr also reported that induction with misoprostol resulted in a more painful labour. ${ }^{13}$

Comparing the overall foetal outcomes of both the groups, there was no significant difference in the foetal outcome in both the groups ( $\mathrm{p}$ value is 0.138 ). Gemund $\mathrm{N}^{14}$ in their study showed that 'Adverse neonatal outcome' was found similar in both groups:

The maternal outcome was similar in both the groups ( $77 \%$ and $84 \%$ ) with $p$ value being 0.138 . Hyperstimulation of the uterus due to induction was a common complication and statistically not significant between misoprostol and dinoprostone gel. ( $\mathrm{p}$ value - 0.238 using chi square test). Postpartum haemorrhage was another common maternal complication ( $9 \%$ and $7 \%$ ) in both the groups. Kulshreshtha S et al ${ }^{15} 2006$ in their study had similar hyperstimulation rates.

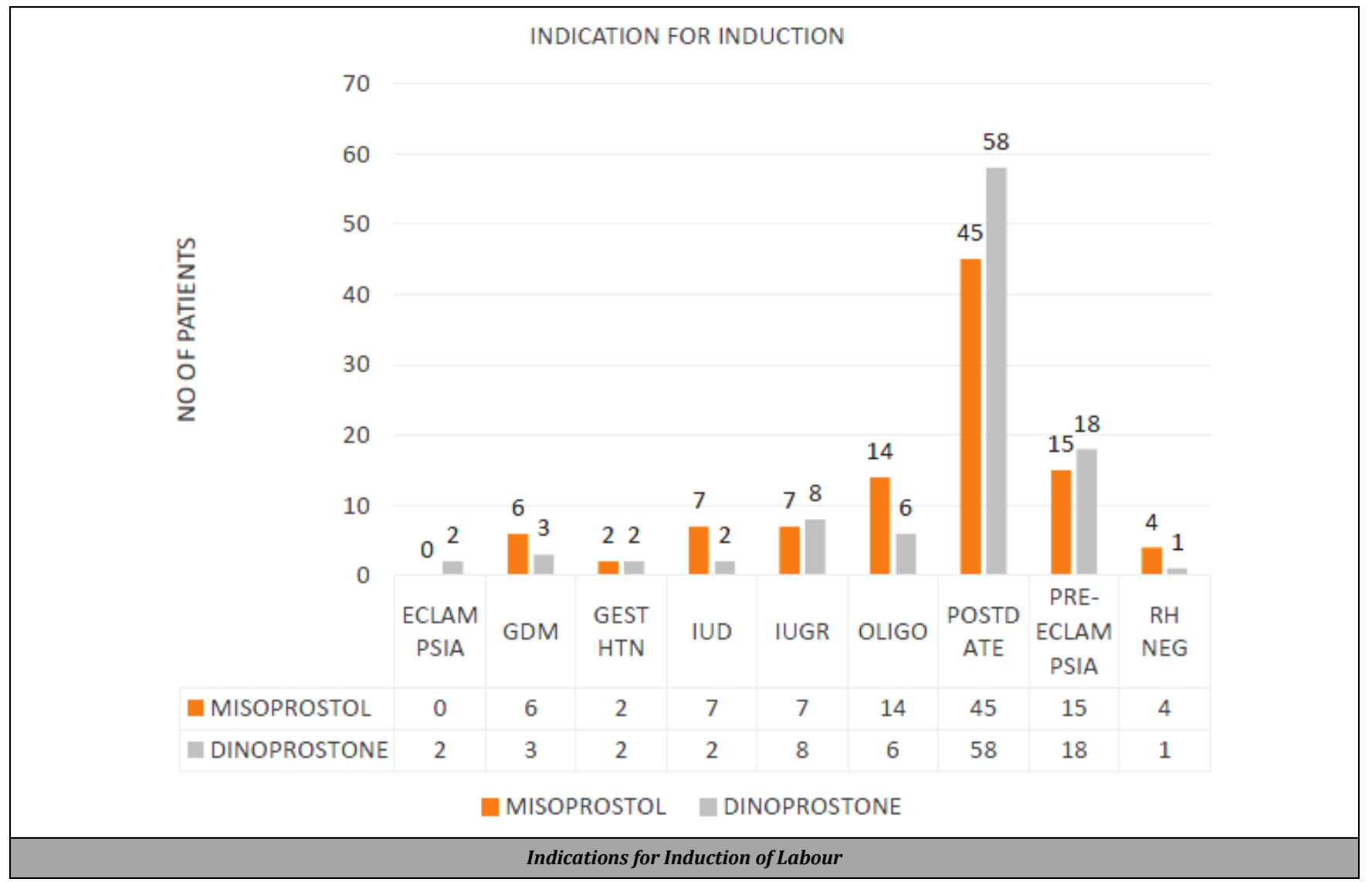




\section{CONCLUSIONS}

Low dose intravaginal misoprostol was equally effective as intracervical dinoprostone gel for cervical ripening. Induction to delivery time was similar in both the groups. Similar incidences of foetal distress and cervical dystocia were noted in both groups. Caesarean rate was significantly less with intravaginal misoprostol group compared to dinoprostone group. Neonatal and maternal outcomes were similar in both the groups and the differences were not significant. Drug related side effects were similar in both the groups.

Financial or Other Competing Interests: None.

\section{REFERENCES}

[1] Houghton Mifflin Company. Induction of labour. In: American Heritage Dictionary eds. The American heritage dictionary. 4th edn. Boston, MA: Houghton Mifflin Harcourt 2006: p. 1074.

[2] Beischer NA. Maternal well-being during pregnancy. In: Beischer NA, Mackay EV, Colditz PB, eds. Obstetrics and the newborn. An illustrated textbook. $3^{\text {rd }}$ edn. Plhiladelphia: Saunders 1997: p. 449.

[3] Witter FR. Prostaglandin E2 preparations for preinduction cervical ripening. Clin Obstet Gynecol 2000;43(3):469-74.

[4] Arias F. Pharmacology of oxytocin and prostaglandins. Clin Obstet Gynecol 2000;43(3):455-68.

[5] Brindley BA, Sokol RJ. Induction and augmentation of labour: basis and methods for current practice. Obstet Gynecol Surv 1988;43(12):730-43.
[6] World Health Organization. Model list of essential medicines 2011. 17th edn. Geneva: WHO 2011. http://www.who.int/medicines/publications/ essential medicines/en/.

[7] National Institute for Health and Care Excellence 2014.

[8] Novakov A, Segedi D, Milasinovic L, et al. Induction of labour by endocervical application of prostaglandins and intravenous infusion of oxytocin in postterm pregnancy. Med Pregl 1998;51(9-10):419-26.

[9] Royal College of Obstetricians and Gynecologists. Induction of labour. Evidence Based Clinical Guideline No. 9. London: RCOG Press 2001:1-90.

[10] Prager M, Eneroth-Grimfors E, Edlund M, et al. A randomised controlled trial of intravaginal dinoprostone, intravaginal misoprostol and transcervical balloon catheter for labour induction. BJOG: An International Journal of Obstetrics and Gynaecology 2008;115(11):1443-50.

[11] Ozkan S, Caliskan E. Comparative safoety and efficacy of vaginal misoprostol versus cerviprime vaginal insert in labour induction at term: a randomized trial. Arch Gynecol Obstet 2009;280(1):19-24.

[12] Nanda S, Singhal SR, Papneja A. Induction of labour with intravaginal misoprostol and prostaglandin E2 gel: a comparative study. Trop Doct 2007;37(1):21-4.

[13] Hofmeyr GJ, Gulmezoglu AM. Vaginal misoprostol for cervical ripening and induction of labour. Cochrane Database Syst Rev 2003;(1):CD000941.

[14] van Gemund N, Scherjon S, Le Cessie S, et al. A randomised trial comparing low dose vaginal misoprostol and dinoprostone for labour induction. BJOG: An International Journal of Obstetrics and Gynaecology 2004;111(1):42-9.

[15] Kulshreshtha S, Sharma P, Mohan G, et al. Comparative study of misoprostol vs dinoprostone for induction of labour. Indian J Physiol Pharmacol 2007;51(1):55-61. 